\title{
ANALISIS PENGARUH PROFESSIONAL IDENTITY DAN WORK ENGAGEMENT TERHADAP TURNOVER INTENTION PADA AGEN ASURANSI ALLIANZ LIFE INDONESIA GENERASI MILENIAL YANG DI MEDIASI OLEH JOB SATISFACTION
}

\author{
Dafa Alfaryaby Ramadhan dan M. Tony Nawawi \\ Program Studi Manajemen/Akuntansi Fakultas Ekonomi Universitas Tarumanagara, Jakarta \\ Email: dafa_seon@yahoo.com
}

\begin{abstract}
The purpose of this study was to analyze the influence of Professional Identity, Job Involvement, Job Satisfaction, and Employee Turnover. This sample collection is done using a non-probability method using purposive sampling technique. The sample of this study is the millennial generation insurance agent in the company Allianz Life Indonesia with a total of 100 respondents. Data were analyzed using the PLS-SEM method with the SmartPLS 3.0 application. The results of this study indicate that Professional Identity is significant and has a positive effect on Job Satisfaction, Job Involvement is significant and has a positive effect on Job Satisfaction, Job Satisfaction is not significant and has a negative effect on Employee Turnover. Professional Identity is not significant and has a negative effect on Employee Turnover, Employee Engagement is not significant and has a negative effect on Employee Turnover. Professional Identity is not significant and has a negative effect on Employee Turnover through Job Satisfaction, and Employee Engagement is not significant and has a negative effect on Employee Turnover through Job Satisfaction.
\end{abstract}

\begin{abstract}
Abstrak: Tujuan dari penelitian ini adalah untuk menganalisis pengaruh Identitas Profesional, Keterlibatan Kerja, Kepuasan Kerja, dan Pergantian Karyawan. Pengumpulan sampel ini di lakukan dengan menggunakan metode non-probability dengan menggunakan teknik purposive sampling. Sampel dari penelitian ini adalah agen asuransi generasi milenial dalam company Allianz Life Indonesia dengan total 100 responden. Data dianalisis menggunakan metode PLSSEM dengan aplikasi SmartPLS 3.0. Hasil penelitian ini menunjukan bahwa Identitas Profesional signifikan dan berpengaruh positif terhadap Kepuasan Kerja, Keterlibatan Kerja signifikan dan berpengaruh positif terhadap Kepuasan Kerja, Kepuasan Kerja tidak signifikan dan berpengaruh negatif terhadap Pergantian Karyawan. Identitas Profesional tidak signifikan dan berpengaruh negatif terhadap Pergantian Karyawan, Keterlibatan Karyawan tidak signifikan dan berpengaruh negatif terhadap Pergantian Karyawan. Identitas Profesional tidak signifikan dan berpengaruh negatif terhadap Pergantian Karyawan melalui Kepuasan Kerja, dan Keterlibatan Karyawan tidak signifikan dan berpengaruh negatif terhadap Pergantian Karyawan melalui Kepuasan Kerja.
\end{abstract}

Keyword: Identitas Profesional, Keterlibatan Kerja, Kepuasan Kerja, Pergantian Karyawan.

\section{LATAR BELAKANG}

Industri keuangan telah menjadi salah satu roda penggerak dalam masalah perekonomian di dalam suatu Negara. Menurut (Rahim, 2013) industri asuransi merupakan salah satu pilar yang mempunyai andil yang cukup besar pada perekonomian di suatu Negara. Industri asuransi merupakan lembaga non bank yang mempunyai peran penting dalam sistem keuangan Indonesia (Djaelani, 2011). Di Indonesia sendiri, permintaan akan asuransi jiwa meningkat diikuti dengan naiknya pendapatan dan kesadaran masyarakat akan pentingnya mengantisipasi 
resiko yang akan muncul di masa yang akan datang (Djaelani, 2011). Dilansir dari (Alifah, 2020) bahwasannya statistik perusahaan asuransi pada tahun 2018 menunjukkan bahwa penduduk Indonesia rata-rata mengeluarkan sebesar Rp.1.635.266 untuk membayar premi asuransi. Meskipun industri asuransi ini cukup meyakinkan akan pertumbuhannya, tetapi masih ada suatu faktor permasalahan yang belum dapat teratasi, yaitu tingginya tingkat turnover intention (Walfajri, 2020). Bahwasannya tenaga pemasaran merupakan aset yang sangat penting bagi industri asuransi dan tenaga pemasaran juga memiliki peran yang penting dalam berkembangnya industri asuransi ini (Reni et al., 2017). Generasi milenial merupakan generasi yang terlahir antara tahun 1980 sampai dengan tahun 2000, yang dimana generasi ini merupakan generasi terbaru yang siap dalam memasuki dunia kerja. Terdapat kualitas positif yang dimiliki oleh generasi milenial. Generasi milenial juga dikenal fokus pada pencapaian, generasi ini beranggapan tidak hanya melakukan sesuatu dengan baik, tetapi unggul serta melampaui semua tujuan maupun aspirasi (Kaifi et al., 2012 \& Kowske et al., 2010). Untuk menarik dan mempertahankan generasi milenial penting bagi sebuah perusahaan untuk memahami yang menjadi motivasi dan memuaskan bagi generasi milenial ini (Smith J Travis \& Nichols Tommy, 2015).

\section{KAJIAN TEORI}

Organozational Support Theory Salah satu aspek kehidupan organnisasi dimana pihak pemberi kerja dan karyawan sama-sama tertarik akan pengembangan manajemen. Dimana pengembangan manajemen merupakan suatu proses dimana karyawan memperoleh kompetensi yang diperlukan guna mencapai efektivitas manajerial (Kumar, 2017).

Professional Identity. Professional Identity merupakan sifat dasar psikologis dari seseorang terhadap kesadaran seseorang tersebut kepada pekerjaannya dan mengidentifikasi orang tersebut dengan dampak sosial dari profesinya (Trede et al., 2012), (Mancini et al., 2015), dan (Zhang et al., 2018).

Work Engagement. Keterlibatan kerja merupakan suatu keadaan baik berupa emosi, prilaku, serta pikiran yang positif yang dialami seorang karyawan untuk melakukan suatu pekerjaan (Lu et al., 2016), dan (Siddiqi, 2013).

Job Satisfaction. Job Satisfaction merupakan keadaan respon emosional positif atau rasa puas seorang sebagai akibat dari sebuah persepsi terhadap suatu pekerjaan (Yukongdi \& Shrestha, 2020), (Murrar \& Hamad, 2013), (Azeez et al., 2016), dan (Kurniawan \& Nawawi, 2020).

Turnover Intention. Turnover Intetion merupakan suatu niat dan sikap yang timbul pada diri seseorang untuk meninggalkan organisasinya (Malik \& Khalid, 2016), dan (Sinem AYDOGDU; Baris ASIKGIL, 2011).

Kaitan Antar Variabel. Identitas profesional telah menjadi faktor yang kuat terhadap kepuasan kerja. Ini menciptakan korelasi antara identitas professional dengan kepuasan kerja mempunyai hubungan signifikan secara statistic positif. (Sabanciogullari \& Dogan, 2015) mengatakan bahwa identitas professional berpengaruh secara signifikan kepada kepuasan kerja dan niat meninggalkan profesinya. (Sabanciogullari \& Dogan, 2015) bahwa profesionalisme yang juga melibatkan identitas professional, diidentifikasi menjadi faktor penting dalam kepuasan karyawan. 
Dalam sebuah penelitian telah terlihat bahwa kepuasan kerja merupakan sebuah evaluasi emosional dari pekerjaan dan telah dikaitkan dengan keadaan setia sedangkan keterlibatan kerja merupakan keadaan motivasi dan terkait dengan aktivasi (Yalabik et al., 2017). Hal ini menandakan ketika seorang karyawan telah mengevaluasi pekerjaan mereka, mereka siap (atau tidak, jika mereka tidak puas) untuk pindah ke dalam keadaan motivasi , yaitu terlibat.

Selanjutnya menarik teori dari Social Exchange Theory dalam (Yalabik et al., 2017) menyarankan bahawasannya hubungan yang berbasis timbal balik antara suatu organisasi dan karyawannya akan dapat memprediksi sikap kerja yang positif dalam selubung kepuasan kerja. Karenanya ketika seorang karyawan puas akan hasil pekerjaan mereka, mereka akan dapat menyediakan organisasi dengan tingkat keterlibatan kerja yang lebih tinggi .

Kepuasan kinerja memiliki pengaruh tehadap untuk menentukan tetap tinggal atau meninggalkan organisasi. Ketika seorang karyawan merasa tidak puas akan hasil dari pekerjaan mereka, karyawan tersebut kemungkinan besar akan meninggalkan organisasinya. Tapi sebaliknya, ketika seorang karyawan yakin bahwa dia akan di perlakukan secara adil dan mendapatkan penghargaan atas hasil dari pekerjaan mereka, kemungkinan besar mereka akan meninggalkan organisasi tersebut (Sinem AYDOGDU; Baris ASIKGIL, 2011)

Meningkatnya identitas profesional seorang karyawan, maka turnover intention dapat dikurang secara efektif. Yang dimana ketika ada seorang karyawan yang berpikir bahwa pekerjaan yang karyawan itu jalani menciptakan suatu nilai yang bermakna bagi dirinya sendiri, maka dia akan memiliki rasa identitas profesional yang tinggi, maka karyawan tersebut akan lebih puas dan banyak terlibat pada organisasi tersebut, sebaliknya ketika seorang karyawan itu memiliki identitas profesional yang rendah, karyawan akan mempertimbangkan meninggalkan pekerjaan dan mengambil peluang yang sesuai yang ada (Wang et al., 2020).

Penelitian yang telah ada menunjukkan bahwasannya karyawan yang terlibat dalam pekerjaan mereka cenderung akan tetap tinggal. Karyawan yang terlibat cenderung memiliki keterikatan yang besar terhadap organisasi mereka dan mempunyai cenderung yang lebih untuk tidak meninggalkan organisasi mereka. Menurut teori pertukaran sosial ini, ketika kedua belah pihak mematuhi aturan yang berlaku menghasilkan hubungan yang saling percaya dan setia serta komitmen timbal balik. Akibatnya, individu yang lebih terlibat cenderung berada dalam hubungan yang lebih dapat dipercaya dan hubungan yang berkualitas tinggi dengan pemberi kerja, oleh karenanya cenderung melaporkan sikap dan niat yang lebih positif terhadap organisasi (Singh et al., 2019).

Para peneliti percaya bahwa identitas profesional memungkinkan karyawan memperoleh sumber daya kerja yang diinginkan secara efektif dan membantu menciptakan suasana kerja yang nyaman, sehingga meningkatkan kepuasan kerja karyawan, yang pada akhirnya mengurangi niat keluar dari karyawan. Hal ini menunjukkan bahwa identitas profesional merupakan faktor kunci yang mempengaruhi kepuasan kerja karyawan. Oleh karenanya kepuasan kerja dapat menjadi mediator, yang menjelaskan efek mediasi antara identitas profesional dan perilaku intensi turnover (Wang et al., 2020).

Job Satisfaction dalam bahasan ini dapat dipengaruhi oleh Work Engagement yang dimana, ketika seorang karyawan tersebut mempunyai Work Engagement yang tinggi maka akan menyebabkan tinggi juga tingkat Job Satisfaction yang dimiliki seorang karyawan tersebut. Karyawan yang memiliki Work Engagement yang tinggi dibanding karyawan lainnya cenderung mempunyai komitmen yang tinggi, keterlibatan kerja yang tinggi, dan terikat kuat dengan pekerjaannya (Merissa, 2018)

Kerangka Pemikiran. Professional Identity $\left(\mathrm{X}_{1}\right)$ dan Work Engagement $\left(\mathrm{X}_{2}\right)$ menjadi variabel independen, kemudian Turnover Intention (Y) sebagai independen, lalu Job Satisfaction (M) 
$\mathrm{H} 4$

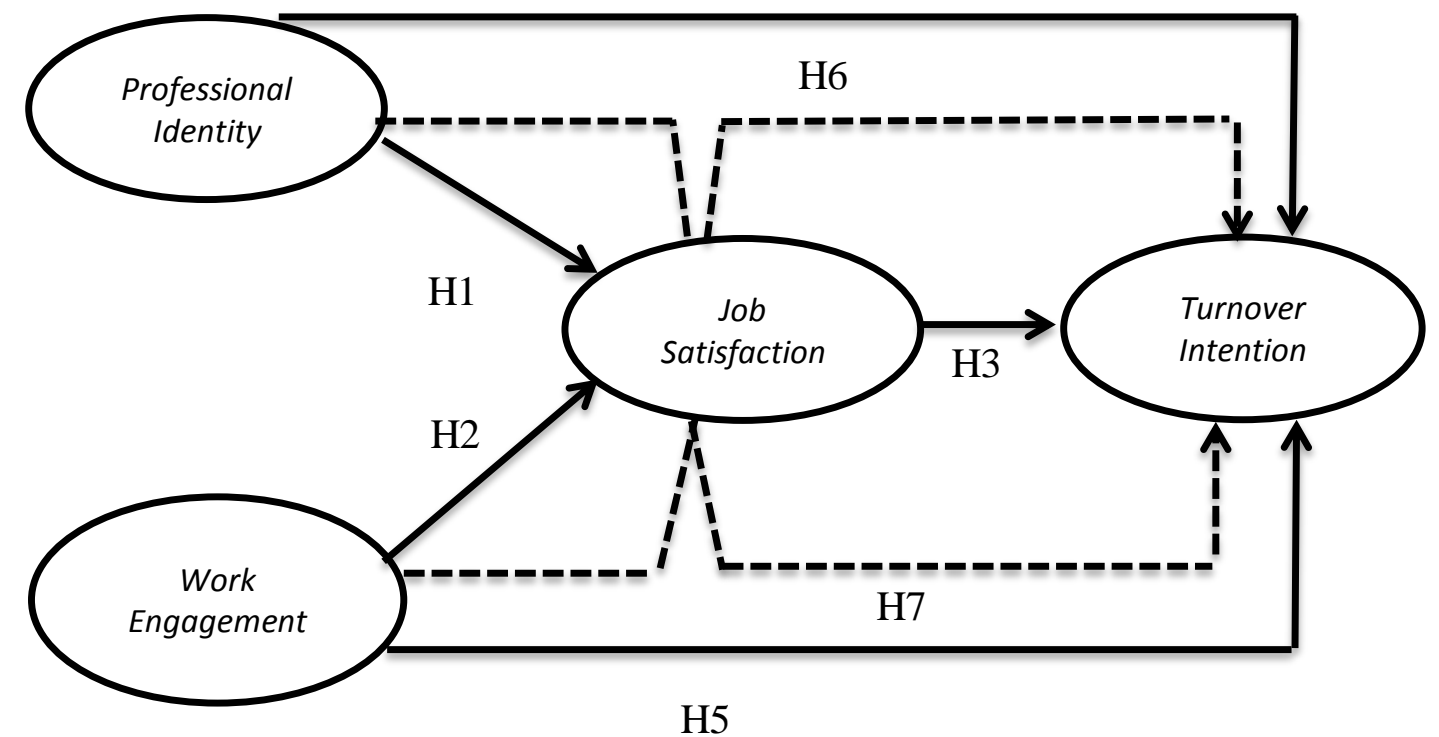

Gambar 2.1 Model Penelitian

\subsection{Hipotesis}

$\mathrm{H}_{1}$ : Professional Identity berpengaruh positif terhadap Job Satisfaction.

$\mathrm{H}_{2}$ : Work Engagement berpengaruh positif terhadap Job Satisfactin.

$\mathrm{H}_{3}$ : Job Satisfaction berpengaruh negatif terhadap Turnover Intention.

$\mathrm{H}_{4}$ : Professional Identity berpengaruh negatif terhadap Turnover Intention.

$\mathrm{H}_{5}$ : Work Engagement berpengaruh negati terhadap Turnover Intention.

$\mathrm{H}_{6}$ : Professional Identity berpengaruh negaif terhadap Turnover Intention melalui Job Satisfaction.

$\mathrm{H}_{7}$ : Work Engagement berpengaruh negatif terhadap Turnover Intention melalui Job Satisfaction

\section{METODOLOGI}

Subjek dan populasi dari penelitian ini adalah agen asuransi Allianz Life Indonesia generasi milenial di Jakarta. Teknik pengumpulan sampel yang peneliti gunakan adalah nonprobability sampling dengan metode purposive sampling dengan ukuran sebanyak 100 responden. Penelitian ini menggunakan teknik analisa PLS-SEM yang terdiri dari dua analisis yaitu outer model dan inner model.

\section{HASIL ANALISIS DATA}

Hasil analisis validitas menunjukkan bahwa setiap variabel telah memiliki nilai lebih dari 0.50 untuk nilai Average Variance Extracted dan memiliki nilai lebih dari 0.70 untuk outer loading. Maka variabel dalam penelitian ini telah memenuhi syarat validitas konvergen. Validitas diskriminan dinyatakan valid jika analisis nilai cross loading tiap indikator lebih besar dibanding nilai cross loading konstruk lainnya. Uji reliabilitas dalam penelitian ini melihat nilai dari analisis composite reliability. Data penelitin dikatan reliabel apabila nilai dari composite reliability menunjukkan angka diatas $0.70(>0.70)$. 
Tabel 4.1 Hasil Average Variance Extracted

\begin{tabular}{|c|c|}
\hline Variabel & Average Variance Extracted \\
\hline Job Satisfaction & 0.701 \\
\hline Professional Identity & 0.648 \\
\hline Turnover Intention & 0.773 \\
\hline Work Engagement & 0.659 \\
\hline
\end{tabular}

Tabel 4.2 Hasil Analisis Outer Loading

\begin{tabular}{|c|c|c|c|c|}
\hline & Job Satisfaction & $\begin{array}{c}\text { Professional } \\
\text { Identity }\end{array}$ & $\begin{array}{c}\text { Turnover } \\
\text { Intention }\end{array}$ & Work Engagement \\
\hline JS1 & $\mathbf{0 . 8 6 9}$ & 0.645 & -0.219 & 0.635 \\
\hline JS2 & $\mathbf{0 . 8 0 3}$ & 0.649 & -0.253 & 0.699 \\
\hline JS3 & $\mathbf{0 . 8 4 0}$ & 0.568 & -0.303 & 0.662 \\
\hline PI1 & 0.621 & $\mathbf{0 . 8 0 5}$ & -0.128 & 0.523 \\
\hline PI2 & 0.597 & $\mathbf{0 . 8 2 5}$ & -0.244 & 0.578 \\
\hline PI3 & 0.564 & $\mathbf{0 . 7 9 8}$ & -0.266 & 0.579 \\
\hline PI4 & 0.658 & $\mathbf{0 . 7 9 1}$ & -0.260 & 0.516 \\
\hline PI5 & 0.527 & $\mathbf{0 . 8 0 5}$ & -0.108 & 0.504 \\
\hline TI1 & -0.268 & -0.236 & $\mathbf{0 . 8 5 1}$ & -0.237 \\
\hline TI2 & -0.223 & -0.195 & $\mathbf{0 . 8 7 1}$ & -0.245 \\
\hline TI3 & -0.313 & -0.239 & $\mathbf{0 . 9 1 5}$ & -0.324 \\
\hline WE1 & 0.719 & 0.601 & -0.245 & $\mathbf{0 . 8 7 7}$ \\
\hline WE3 & 0.579 & 0.530 & -0.179 & $\mathbf{0 . 7 5 4}$ \\
\hline WE4 & 0.657 & 0.550 & -0.268 & $\mathbf{0 . 7 9 5}$ \\
\hline WE5 & 0.622 & 0.499 & -0.308 & $\mathbf{0 . 8 1 5}$ \\
\hline
\end{tabular}

Tabel 4.3 Hasil Analisis Composite Reliability

\begin{tabular}{|c|c|}
\hline VARIABEL & Composite Reliability \\
\hline Job Satisfaction & 0.876 \\
\hline Professional Identity & 0.902 \\
\hline Turnover Intention & 0.911 \\
\hline Work Engagement & 0.885 \\
\hline
\end{tabular}

Hasil uji multikolineritas (Tabel 4.4) menguji apakah terdapat korelasi antar variabel di dalam model regresi dalam penelitian ini dan dikatakan baik karena memiliki nilai VIF kurang dari 10. Karenanya tidak terdapat multikolineritas antar variabel bebas. Lalu ada hasil uji analisis R-square menunujukkan pengaruh menunjukkan nilai 1 yang yang mewakili akurasi prediktif paling lengkap. Kemudian nilai koefisien determinan (Tabel 4.5) dalam penelitian ini dari masing-masing variabel memiliki tingkatan sedang dan kecil karena setiap variabel memiliki nilai 0.713 dan 0.107. Maka bisa dikatakan bahwa variabel eksogen memiliki pengaruh sedang dan variabel eksogen lain memiliki pengaruh kecil untuk mempengaruhi variabel endogen. Terakhir hasil analisis predictive relevance $\left(\mathrm{Q}^{2}\right)$ (Tabel 4.5) pada peneltian ini dapat dikatakan baik karena memiliki nilai lebih besar daripada $0(>0)$. Sehingga menunjukkan bahwa model memiliki predictive relevance . 
Tabel 4.4 Hasil Uji Multikolinearitas

\begin{tabular}{|l|c|c|c|c|}
\hline & Job Satisfaction & $\begin{array}{c}\text { Professional } \\
\text { Identity }\end{array}$ & $\begin{array}{c}\text { Turnover } \\
\text { Intention }\end{array}$ & Work Engagement \\
\hline Job Satisfaction & & & 3.481 & \\
\hline $\begin{array}{l}\text { Professional } \\
\text { Identity }\end{array}$ & 1.824 & & 2.320 & \\
\hline $\begin{array}{l}\text { Turnover } \\
\text { Intention }\end{array}$ & & & & \\
\hline Work Engagement & 1.824 & & 2.849 & \\
\hline
\end{tabular}

Tabel 4.5 Hasil Analisis R Square dan Q Square

\begin{tabular}{|c|c|c|}
\hline VARIABEL & R Square & Q Square \\
\hline Job Satisfaction & 0.713 & 0.484 \\
\hline Turnover Intention & 0.107 & 0.065 \\
\hline
\end{tabular}

Tabel 4.6 Hasil Analisis Path Coefficient, Signifikansi, dan Effect Size

\begin{tabular}{|l|c|c|c|c|}
\hline \multicolumn{1}{|c|}{ Hipotesis } & $\begin{array}{c}\text { Path } \\
\text { Coefficient }\end{array}$ & $\begin{array}{c}\boldsymbol{T} \text { - } \\
\text { Statistics }\end{array}$ & $\boldsymbol{p}^{\text {-value }}$ & $\mathbf{f}^{\mathbf{2}}$ \\
\hline Professional Identity - Job Satisfaction & 0.378 & 5.322 & 0.000 & 0.272 \\
\hline Work Engagement - Job Satisfaction & 0.543 & 6.674 & 0.000 & 0.562 \\
\hline Job Satisfaction - Turnover Intention & -0.154 & 1.041 & 0.298 & 0.008 \\
\hline Professional Identity - Turnover Intention & -0.028 & 0.183 & 0.855 & 0.000 \\
\hline Work Engagement - Turnover Intention & $\mathbf{- 0 . 1 6 8}$ & 1.145 & 0.253 & 0.011 \\
\hline
\end{tabular}

Tabel 4.9 Hasil Analisis Path Coefficient dan Signifikansi

\begin{tabular}{|c|c|c|c|}
\hline Hipotesis & Path Coefficient & & $p$-value \\
\hline $\begin{array}{l}\text { Professional Identity - Job Satisfaction - Turnover } \\
\text { Intention }\end{array}$ & -0.058 & 1.050 & 0.294 \\
\hline Work Engagement - Job Satisfaction - Turnover Intention & -0.084 & 0.964 & 0.335 \\
\hline
\end{tabular}

\section{DISKUSI}

\section{Tabel 5.1 Kesimpulan Hasil}

\begin{tabular}{|c|l|c|}
\hline HIPOTESIS & \multicolumn{1}{|c|}{ PERNYATAAN HIPOTESIS } & HASIL \\
\hline $\mathrm{H}_{1}$ & Professional Identity - Job Satisfaction & Didukung \\
\hline $\mathrm{H}_{2}$ & Work Engagement - Job Satisfaction & Didukung \\
\hline $\mathrm{H}_{3}$ & Job Satisfaction - Turnover Intention & Ditolak \\
\hline $\mathrm{H}_{4}$ & Professional Identity - Turnover Intention & Ditolak \\
\hline $\mathrm{H}_{5}$ & Work Engagement - Turnover Intention & Ditolak \\
\hline $\mathrm{H}_{6}$ & $\begin{array}{l}\text { Professional Identity - Job Satisfaction - Turnover } \\
\text { Intention }\end{array}$ & Ditolak \\
\hline $\mathrm{H}_{7}$ & $\begin{array}{l}\text { Work Engagement - Job Satisfaction - Turnover } \\
\text { Intention }\end{array}$ \\
\hline
\end{tabular}




\section{PENUTUP}

Berdasarkan hasil penelitian maka dapat disimpulkan bahwa professional identity memiliki pengaruh terhadap job satisfaction, work engagement memiliki pengaruh terhadap job satisfaction, job satisfaction tidak memiliki pengaruh terhadap turnover intention, professional identity tidak memiliki pengaruh terhadap turnover intention, work engagement tidak memiliki pengaruh terhadap turnover intention, job satisfaction tidak dapat memberikan efek mediasi antara variabel professional identity dengan turnover intention, serta job satisfaction tidak dapat memberikan efek mediasi antara variabel work engagement dan turnover intention. Berdasarkan penelitian yang telah dilakukan, peneliti akan memberikan berapa saran yang diharapkan dapat berguna bagi perusahaan. Disarankan company untuk lebih banyak membuat program program baru yang sejalan dengan pemikiran generasi millennial saat ini. Lalu disarankan untuk para agen generasi milenial untuk membuat target yang harus dicapai oleh dirinya sendiri.

\section{DAFTAR PUSTAKA}

Alifah, N. S. (2020). Perkembangan Asuransi di Indonesia [Plus Daftar Asosiasinya]. Lifepal.Co.Id. https://lifepal.co.id/media/data-perkembangan-asuransi-di-indonesia/

Azeez, R. O., Folusollesanmi, J., \& Olarewaju, A. A. (2016). Job satisfaction , organizational commitment, turnover intention, and ... Personnel Psychology, 8(2), 259-293. https://www.researchgate.net/publication/316885080

Djaelani, F. et. al. (2011). Pertumbuhan Industri Asuransi Jiwa Di Indonesia: Suatu Kajian Dari Sisi Penawaran. Jurnal Kawistara: Jurnal Ilmiah Sosial Dan Humaniora, 1(3). https://doi.org/10.22146/kawistara.3925

Kaifi, B. A., Nafei, W. A., Khanfar, N. M., \& Kaifi, M. M. (2012). A Multi-Generational Workforce: Managing and Understanding Millennials. International Journal of Business and Management, 7(24), 88-93. https://doi.org/10.5539/ijbm.v7n24p88

Kowske, B. J., Rena, R., \& Wiley, J. (2010). Millennials' (lack of) attitude problem: An empirical examination of generational effects on work attitudes. Journal of Business and Psychology, 25(2), 265-279. https://doi.org/10.1007/s10869-010-9171-8

Kumar, M. et. al. (2017). Managerial support for development and turnover intention Roles of organizational support, work engagement and job satisfaction. https://doi.org/10.1108/JOCM-06-2017-0232

Kurniawan, J. A., \& Nawawi, M. T. (2020). Pengaruh Kompensasi Motivasi dan Kepuasan Kerja terhadap Kinerja Karyawan PT. Kurnia Mandiri Jaya pada Divisi. II(3), 2.

Lu, L., Lu, A. C. C., Gursoy, D., \& Neale, N. R. (2016). Work engagement, job satisfaction, and turnover intentions: A comparison between supervisors and line-level employees. International Journal of Contemporary Hospitality Management, 28(4), 737-761. https://doi.org/10.1108/IJCHM-07-2014-0360

Malik, S. Z., \& Khalid, N. (2016). Psychological contract breach, work engagement and turnover intention. Pakistan Economic and Social Review, 54(1), 37-54. https://www.jstor.org/stable/26616697

Mancini, T., Caricati, L., Panari, C., \& Tonarelli, A. (2015). Personal and social aspects of professional identity.. An extension of Marcia's identity status model applied to a sample of university students. Journal of Vocational Behavior, 89, 140-150. https://doi.org/10.1016/j.jvb.2015.06.002

Merissa, B. (2018). Pengaruh Work Engagement Terhadap Turnover Intention Melalui Job Satisfaction Sebagai Variabel Mediasi Pada PT. Lotte Shopping Indonesia Sidoarjo. Jurnal Agora, 6(1), 1-9. http://publication.petra.ac.id/index.php/manajemenbisnis/article/view/6485 
Murrar, A., \& Hamad, A. (2013). RELATIONSHIP BETWEEN JOB SATISFACTION AND TURNOVER INTENTION: An Empirical Study on the IT Firms in Palestine. Interdisciplinary Journal of Research in Business, 2(8), 2046-714167.

Rahim, H. (2013). Optimisme Pertumbuhan Asuransi Indonesia. Jurnal Asuransi Dan Manajemen Resiko, 1, 1-21. http://s3.amazonaws.com/academia.edu.documents/36863876/asuransi_umum.pdf?AWS AccessKeyId=AKIAIWOWYYGZ2Y53UL3A\&Expires $=1492265862 \&$ Signature $=x g v Z$ p596QsNThY8RvXfH1RGtRno\%3D\&response-content-disposition=inline\%3B filename\%3DAsuransi_umum.pdf

Reni, M., Jatmika, D., Psikologi, F., \& Mulia, U. B. (2017). Hubungan Resiliensi Dengan Work Engagement Pada Agen Asuransi Pt X Relationship Between Resiliency With Work Engagment Insurance Agents in. Jurnal Ecopsy, 4(2), 117-123.

Sabanciogullari, S., \& Dogan, S. (2015). Relationship between job satisfaction, professional identity and intention to leave the profession among nurses in Turkey. Journal of Nursing Management, 23(8), 1076-1085. https://doi.org/10.1111/jonm.12256

Siddiqi, M. A. (2013). Examining Work Engagement as a Precursor to Turnover Intentions of Service Employees. International Journal of Information, Business and Management, 5(4), 118-133.

Sinem AYDOGDU; Baris ASIKGIL. (2011). An Empirical Study of the Relationship Among Job Satisfaction , Organizational Commitment and Turnover Intention. International Review of Management and Marketing, 1(3), 43-53.

Singh, R., Ramgulam, N., Lewis, R., \& Ramdeo, S. (2019). An Investigation into Caribbean Hotel Employees' Personality, Work Engagement, Job Satisfaction and Turnover Intentions. Journal of Eastern Caribbean Studies, 44(1), 23-48.

Smith J Travis \& Nichols Tommy. (2015). Understanding the Millennial Generation. Journal of Financial Service Professionals, 69(6), 11-14. http://eds.a.ebscohost.com.laureatech.idm.oclc.org/eds/pdfviewer/pdfviewer?sid=0a0336 d0-b8da-410d-a5b3-7e42fa4cbe86@ sessionmgr4004\&vid=1\&hid=4210

Trede, F., Macklin, R., \& Bridges, D. (2012). Professional identity development: A review of the higher education literature. Studies in Higher Education, 37(3), 365-384. https://doi.org/10.1080/03075079.2010.521237

Walfajri, M. (2020). AAJI: Turnover tinggi bikin asuransi jiwa terus rekrut agen walau ada pandemi. Kontan.Co.Id. https://keuangan.kontan.co.id/news/aaji-turnover-tinggi-bikinasuransi-jiwa-terus-rekrut-agen-walau-ada-pandemi

Wang, C., Xu, J., Zhang, T. C., \& Li, Q. M. (2020). Effects of professional identity on turnover intention in China's hotel employees: The mediating role of employee engagement and job satisfaction. Journal of Hospitality and Tourism Management, 45(June), 10-22. https://doi.org/10.1016/j.jhtm.2020.07.002

Yalabik, Z. Y., Rayton, B. A., \& Rapti, A. (2017). Facets of job satisfaction and work engagement. Evidence-Based HRM, 5(3), 248-265. https://doi.org/10.1108/EBHRM-082015-0036

Yukongdi, V., \& Shrestha, P. (2020). The Influence of Affective Commitment, Job Satisfaction and Job Stress on Turnover Intention: A Study of Nepalese Bank Employees. Review of Integrative Business and Economic Research, 9(1), 88-98.

Zhang, W., Meng, H., Yang, S., \& Liu, D. (2018). The influence of professional identity, job satisfaction, and work engagement on turnover intention among township health inspectors in China. International Journal of Environmental Research and Public Health, 15(5). https://doi.org/10.3390/ijerph15050988 